\title{
Becoming a Culturally Proficient Teacher in These Turbulent Times
}

\author{
Patricia Nugent ${ }^{1} \rtimes$ \\ Heljä Antola Crowe ${ }^{2}$ (D) \\ Pamela Faber ${ }^{3}$ (D) \\ ' Associate Professor, Bradley University, USA \\ Email:pmugent@fsmail.bradley.edu Tel:309-677-3176 \\ ${ }^{2}$ Professor, Bradley University, USA \\ Email:helia@fmail.bradlev.edu Tel:309-677-2521 \\ ${ }^{s}$ Independent Educational Consultant, USA \\ Email:pfaber57@gmail.com Tel:630-677-8770
}

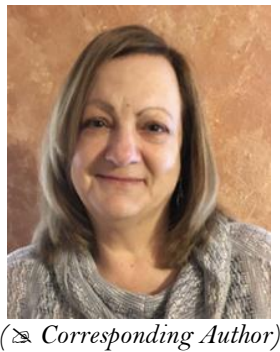

Corresponding Author

\begin{abstract}
"We teach who we are" (Palmer, 2007) is an important self-revelation. Given the current culture in America, there is much unrest in our classrooms and schools. As teacher educators, we need to be aware of the various cultures influencing not only our classrooms, but also the classrooms of our students and the society at large. This article discusses how cultural awareness and culturally proficient teaching can impact individual instructors and learning environments of their classrooms. As future teachers experience culture in our university classrooms, they are becoming aware of their own cultural identity and its effects on their future students.
\end{abstract}

Keywords: Cultural diversity, Reflective practitioner, Culturally proficient instructor.

Citation | Patricia Nugent; Heljä Antola Crowe; Pamela Faber (2018). Becoming a Culturally Proficient Teacher in These Turbulent Times. Asian Journal of Social Sciences and Management Studies, 5(1): 1-7.

History:

Received: 4 December 2017

Revised: 15 January 2018

Accepted: 22 January 2018

Published: 26 January 2018

Licensed: This work is licensed under a Creative Commons Attribution 3.0 License (c))

Publisher:Asian Online Journal Publishing Group
Contribution/Acknowledgement: All authors contributed to the conception and design of the study.

Funding: This study received no specific financial support.

Competing Interests: The authors declare that they have no conflict of interests.

Transparency: The authors confirm that the manuscript is an honest, accurate, and transparent account of the study was reported; that no vital features of the study have been omitted; and that any discrepancies from the study as planned have been explained.

Ethical: This study follows all ethical practices during writing.

\section{Contents}

1. Introduction

2. Theoretical Frameworks

3. Autobiographical Portraits

4. Autobiography Impacting Instruction

5. Conclusion

References 


\section{Introduction}

In many countries teachers are truly valued and revered. Teacher voices are sometimes not taken seriously in the public discourse and the political arena in the U.S. Darling-Hammond et al. (2010) assert that in high-achieving countries teachers receive a government-provided high-quality education, earn competitive salaries, are mentored with reduced course loads, are provided extensive opportunities for professional development, and are involved in curricular decisions. In the U.S., however, beginning teachers find themselves with inadequate salaries, in demanding environments, and with little support. Too frequently, the least prepared, least supported teachers find themselves in schools with the most educationally vulnerable population. This phenomenon frequently results in a revolving door in the schools that are most in need of stability.

As we move into the second quarter of the twenty-first century, the urgency of preparing culturally proficient teachers is one critical aspect for institutions who prepare teachers for the future. Multiple writers and frameworks developed for 21 st century skills agree that collaboration and working with others is important in the world where we are encountering challenges and problems previously not experienced (Framework for 21 st century skills. Retrieved from http://www.p2 1.org/overview). We posit that as Culturally Proficient Instructor(s) (CPI(s)) (NuriRobins et al., 2012) the valued and essential aspects of public education can and will be preserved. As CPIs, our teacher candidates will be better prepared for the environments they find themselves in as they enter the profession.

We focus here on professional growth through the use of the autobiographical lens (Busse et al., 2000) to shed light on our growth as professors of teacher education. In analyzing the situational objective conditions with the interpretation or subjective explanation of them (Pinar et al., 1996) we discuss professional development in us as professors. We are interested in a multitude of questions that our dialogue is bringing up. What do we and our students use as anchor points to maneuver in our classes? What happens in the family dynamics in relation to their immigrant, "middle of everywhere" (Pipher, 2002) experiences as they negotiate living and working in communities that may or may not understand their functioning, let alone being afraid of being deported? What autobiographical events can we use to strengthen daily realities when we encounter unexpected and new situations with our student? What about the outsider/insider experience in new environments? How do we decide whether to belong or not to belong in a certain situation?

\section{Theoretical Frameworks}

As a framework for discussing culturally proficient individuals, we use the Nuri-Robins et al. (2012) continuum. In these six stages, one sees the difference in culture but responds in different ways. An individual can choose to stomp the cultural difference out, make the difference wrong, act like they don't see the difference, respond inadequately, understand the difference the cultural difference makes or can respond effectively in a variety of environments. This movement is affected by how one enters the situation, as well as how they interpret them as we are going through the process of thinking about them. Curiosity can propel us forward. The fear of uncertainty, the breaks between the thoughts we have and how to take action may propel us backward. As our teaching experiences become more diverse, our need to interact with courage should increase. This metacognitive stance, reflective practitioner mentality (Schön, 1987) is crucial in growing as a professional.

Nuri-Robins et al. (2012) use their culturally proficient continuum to define the qualities of CPIs. CPIs have a certain way of being. They have a mind-set or a mental model where they develop a worldwide view. They view themselves, others, organizations and communities with a multi-faceted lens. They are able to interact effectively with others. They have the ability to negotiate new cultural situations with humility and courage and are open to individuals they interact with. CPIs are culturally aware, value diversity, manage the dynamics of difference, adapt to diversity and institutionalize cultural knowledge. CPIs are aware of how their own culture, and their students' culture impacts instruction, learning and establishment of classroom environment. CPIs appreciate, welcome and elicit diversity with their students. They recognize that conflict is a natural part of life and that conflicts between people may actually stem from conflicts in culture. Since conflict is a natural occurrence, it is important that we are equipped with strategies to deal with conflict. Lastly, CPIs are committed to lifelong learning pertaining to cultural and an institutional acceptance of cultural proficiency. They accept that there is a hidden curriculum, an added layer of interactions, and that it is critical to incorporate facets of cultural proficiency into classroom environments. It is imperative that instructors can be intentional in their approach to cultural acceptance. Self-understanding influence teachers' level of culturally proficient instruction.

\section{Autobiographical Portraits}

Portions of our cultural autobiographical portraits are shared here so that the reader can view the intricacies of our lives, not as a model but as reminder that every life is culturally significant. We encourage the reader to reflect on your own personal journey to see how each life experience informed you and gives you possible alternatives to meet each individual where they are. We define culture not only as international travels and encounters, but also those less obvious types of culture such as gender, race, rural/urban, generation, social, religious, marital, economic and parental experiences, just to name a few. A variety of international cultures and other cultural experiences impact our views of life and how we live our interactions with teacher candidates.

\section{Portrait 1}

I grew up in a small, rural town in southern Illinois where a fourth of the students were 'colored'. I remember playing with both white and black friends on the playground which was located next to the abandoned Colored School which had been desegregated in 1952. During lunch one day in my freshman year, I was called a 'white honky bitch' by one of my black friends. I remember how hurt I was. I remember my Dad telling me that I had better never bring a boyfriend into his house who was of a different race ("black or Jap"). I remember the race riots in the 1970's, the Vietnam War, civil unrest in East St. Louis, JFK, Bobby Kennedy and Martin Luther King Jr.'s assassinations. Before graduating from high school, my family moved to a town on the east side of St. Louis where to this day there are no African-American families. The only cultural diversity in that 
small village was the difference in Christian faiths. I was once asked "Aren't you afraid of going to hell?", since I was not raised in the Catholic church. Needless to say, I was raised with limited cultural diversity and I feel that I grew up ignorant and wanting to know more about others and embracing human diversity. It wasn't until I was in my thirties and I found myself widowed, raising two small children by myself, that I found myself asking God; why?

I ended up changing churches. I remember listening to missionaries' accounts of their travels to places like Africa and Russia. One person even talked about his work on Native American reservations. One of the guest speakers suggested that if you were interested in working as a missionary, then ask God where He wanted to send you, to look at a globe and picture yourself traveling to such a place. He recommended that if I was serious about wanting to go, then I should get ready by getting a passport. The next day I filled out my first passport application. By this time, I had finished my undergraduate and Master's degree and was teaching middle school mathematics. Time passed, my children grew up, and I ended up going to graduate school. Upon arriving at graduate school in central Illinois, I remember thinking I was in a virtual melting pot of cultural diversity. My office mate told me that she did not consider this college town being anything near cultural diversity. She also said that she would never go home with me to meet my family because she would have been the only black person and she said, "I do not put myself in those types of situations". I also remember telling her that I did not see color when I looked at a person and that I didn't care if they were pink, purple, or polka-dotted. She scolded me and told me that I needed to open my eyes and really look because she was a black woman and that it was important that I see her for who she was. I remember going with another African-American friend of mine to the university's Black Graduate Association and being the only white person there. I felt very uncomfortable and out of place when people wouldn't sit by me and I could hear people whispering, "what is she doing here?" As time passed, I completed my doctorate, and took my first university teaching position in Chicago.

By then my passport had expired and I had pretty much forgotten about wanting to travel to work in another part of the world. In April 2015, I was at the National Council of Teachers of Mathematics (NCTM) conference walking through the exhibit booths and saw these brightly colored fabrics and wondered why they there being displayed at a math conference. Being a quilter, my curiosity was peaked, so I started up a conversation with the person manning the booth. He told me about the organization Teachers to Teachers, International (t2t-i) that arranges for teachers in the U.S. to travel to other countries (usually during the summer) and work with teachers and their students through both professional development workshops and in-class collaboration and team-teaching. I updated my passport and decided to travel to Guatemala during August 2015.

The school that I worked in was New Hope School in Chinautla, Guatemala, which is located just north of the capital city. New Hope was built by an American sponsored organization, therefore, it felt "Americanized". Although all the teachers and students were Guatemalan, I was not sure if all Guatemalan schools had access to the amount of technology and manipulatives that this school had. The class size was relatively small also, 25 students per classroom. I worked with the pre-K teacher that first year. She had just been asked to teach the four-year-old class after teaching Kindergarten. I believe that she thought that she had been demoted and being asked to have a college professor observe her classroom did not assure her that her assumption was not correct. I was initially met with resentment.

After my first trip, I came back so excited and on fire through my travel that I wanted all my students to experience what I had just been introduced to. Several of my elementary math content students said that they were interested in studying abroad. I went to my department chair and she suggested that I contact the study abroad coordinator. It was suggested that I write and submit my own study abroad course. I went back to my students and asked them, "If you could design the study abroad experience that best meets your expectations, what would it look like?" I took their suggestions and wrote a study abroad course to Guatemala and it was approved by the university.

When I was planning on going back to Guatemala the following year, I wanted to have a more realistic cultural experience and ended up spending three weeks. I went back to New Hope to keep up the relationships I had with the teachers there and then chose to travel to Santa Avelina, a rural town in the department of El Quiche. Santa Avelina is a two-day bus ride from Guatemala City. It is a beautiful small town surrounded by mountains where coffee trees, bananas, and corn grow up the mountain sides. I volunteered for a week where we team-taught with the teachers, worked with the students, and did professional development with the teachers after school. Our lodging consisted of cots placed in classrooms and we ate all our meals at the school. Lunch and dinner were prepared by volunteers within the community and consisted of hand-pressed corn tortillas, fresh eggs, refried black beans, and plantains. To say the least, I was experiencing being steeped in the Guatemalan culture, spending a week touring the cities of Antigua and the cities surrounding Lake Atitlan. Antiqua is a beautiful city where you feel like you have walked back into time to colonial 1770. The trip back to New Hope meant that I was back in Guatemala City with a population of 2.3 million people. In order to get to New Hope, we traveled through what is called a "red zone", which means the area experiences a great deal of violence through gang wars.

As I continue to reflect on my own childhood and working in a third world country, my parents would tell my siblings and me how poor we were growing up. We grew our own food, home canned vegetables for the winter, and butchered our own meat. I empathize with people living in poverty and agrarian culture. I had to take a trip outside of myself to find another aspect of myself. I was raised in a black and white world, both literally and figuratively. Now, I feel that I live my life in color, due to my cultural experiences.

\section{Portrait 2}

I was born the eldest child of three in the 1960's in a small town outside of Chicago, Illinois. My family has lived in the U.S. for a long time. In fact, we know of relatives that have fought in wars such as Desert Storm, the Korean War, World War II, World War 1 and the Civil War. The main issue of diversity that separated the small farming town I grew up in was whether you were Catholic or Methodist. When I was young, we traveled to Canada. I remember the feeling of being in another country. I am not sure if my parents were anxious or excited, however, I do remember the fear that we had to "cross the border".

My next memory of being outside of the United States occurred while I was an undergraduate. My friend was from Puerto Rico, a U.S. Territory. However, with Spanish being the main language spoken I felt very isolated on both of my visits there. Even though I was learning Spanish, I was not able to keep up with the conversations that were occurring around me. This was the first time I remember being the outsider and thinking, "Are they laughing at me?", as my friend and her grandmother started to laugh after a prolonged conversation in Spanish. Her grandma spoke no English, so they had to speak in Spanish in order to communicate. As I spent more time in their presence, I grew to accept that they were not laughing at me...they were simply sharing a loving, funny memory with each other. I so longed to be able to communicate with her abuela. She had such 
loving eyes and knowing that she had left Cuba, I knew she had so many stories in her heart that I would never be able to know in her own words.

I started teaching in an inner-city urban school of 2400 students. The student population was approximately one-third Latino, one-third Black and one-third Caucasian. It was in the mid-eighties and there was a lot of gang violence occurring in the community. In fact, in the month I started, a police officer was shot and killed just blocks from the school where I taught. There were so many different cultures that I needed to be aware of .. ethnicity, SES level, religion, and language just to name a few. In the midst of all of this, it was my responsibility to teach my students mathematics. I learned quickly that caring, fairness and fortitude were valued virtues in an urban high school teacher. The experiences I had during these years contributed to the teacher and person I am today.

Another culture that may be overlooked is the cultural of living in a single-parent home. The years when my children were younger and I was the main support for them were truly some of the most emotionally, physically, and economically-trying times of my life. Anyone who has been a single-parent can relate to the evening when your child comes home with a school project that is due tomorrow, or even in two days and you do not have the poster, glue, markers, t-shirt, or craft-sticks needed to complete the project. You find yourself trying to figure out how you are going to get to the store to get the materials, and find the time to complete the project. I have been able to use these life-experiences in my classroom to encourage my students to keep in mind the real-world their students and parents are living.

When I started teaching at the collegiate level, it was expected that I present at national and international conferences, so I obtained my first passport. Since that time, I have presented in Jyväskylä, Finland; La Manzanilla, Mexico; Singapore; and Santa Avelina, Guatemala. In each of these experiences I learned invaluable lessons. In Finland, I felt the total isolation of not understanding the spoken or written language around me. At least when I was in Puerto Rico, I could understand some of the spoken and written word. One story I love to share is when my colleague and I were exiting a taxi cab. She spoke fluent Finnish and was conversing with the driver. When I exited the cab, the driver said, "Tonks". I thought, I can say that. So, I replied "Tonks" (thinking this was Finnish for Thanks), to which he and my colleague broke out in laughter. My first thought was, oh no, now what did I say? After my colleague paid the driver, she explained that the driver was trying to speak English and his explicit of "Tonks" was in fact, his version of "Thanks". When I learned this, I too, was able to laugh at the miscommunication.

While in Mexico, during our presentation, I learned another unforgettable lesson about communication. We were presenting on using body movements to accentuate number sense on the number line. During the presentation, we had participants create a number line where one participant was representing two, another representing zero and another representing negative two. We asked someone to go to negative two and one-third and the participant located herself between zero and negative two. I thought, how embarrassing for her and what do we do next? There was a buzz in the room where you knew that not everyone agreed with her placement on the number line. Soon, one of the participants/interpreters stated, "I see what is going on." He explained that for this Spanish speaker the word 'and' meant 'to add'. Therefore, for her, negative two and one-third meant negative two add a positive one-third which summed to be negative one and two-thirds. This explained her moving to a position between negative two and zero (Nugent and Grant, 2011).

In Santa Avelina, Guatemala, I found myself in an environment where the teachers' and children's native language was Ixil and Spanish was their second language. Because the children were working with addition and subtraction with numbers less than twenty, I was actually able to work one-on-one with students using Spanish, the second language for both of us. It was an unforgettable, rewarding experiences. This experience confirmed the importance of a common vocabulary, and the universality of mathematics. Add or mas, subtract or menos, they are the same concepts, just different names.

I have learned what it feels to be the outsider, the one who doesn't understand what is being said, the person who pays for a bottle of water and not knowing what the price is just shows the clerk a wad of money and trusts that they will take the bill that is needed to pay. If I hadn't had the courage to step out of my little town, my safe environment, my cultural comfort zone, I would have missed out on so much. Because of my courage and opportunities, I have seen pagan and Catholic worshippers praying on the same church step, in Guatemala. I have seen beautiful landscapes, heard melodic ocean waves and cultural music, smelled foods that I hadn't heard of, and walked paths to places of this earth that few have had the privilege to see.

In addition to travels I have friends and students from other countries. During my junior year in high school, a family in my community was a host-family for a girl from Sweden. We became friends and continued to write letters after she returned to her home country. During my doctorate studies, I had friends from Mauritius, South Africa, Ethiopia, and Portugal. Due to the demands of the program and our nurturing natures we all became a family during our time together. I have also had the opportunity to teach students from Laos, Mexico, Vietnam, East Germany, and Kosovo. I still remember distinct stories from the interactions and conversations I have had with each of them. I believe that they are all still a part of who I am, who I have become.

I am able to take all of this and help the future teachers I work with see that their view is only one view. It is when we have multiple views of the same situation, same culture, same time that we can have a clearer view of what truly exists. We need to be aware and willing to acknowledge that each child that sits in our class has their own culture, their own experiences, their own influences that creates and influences who they are, who they want to be, and who they will become.

\section{Portrait 3}

As a naturalized U.S. citizen and a dual citizen with Finland, an alien for many years, I have lived and taught early childhood in both countries and teachers in the U.S. in Mississippi and Illinois for close to three decades. Professional visits to South Korea, China, Nicaragua, Australia and many European countries have deepened my understanding of global issues within education. I have taken our university students on Study Abroad experiences to China and Finland, a country currently known for its strengths in education and particularly in teacher preparation.

International experiences in publishing, collaborative projects and presenting scholarly papers, workshops, conference presentations and other teaching experiences in various venues have enlarged my perspective in cross-disciplinary thinking and interactions (Antola Crowe et al., 2016). The variety of professionals I have taught (teachers at all levels, nurses, engineers, lawers and medical doctors) and parents of children in various communities have given me tools to approach teaching situations that are less familiar to me but have excited me to work outside of my disciplinary, national and cultural boundaries. 
Regardless of what teaching experiences I have had (including age level, profession, or geographical location), the issues of acceptance of differences, curiosity and respect for others are common in every workplace and institution regardless of the age, country or region of learners.

My passion is helping university students to become cross-culturally proficient and courageous in taking steps to find the urge to step outside of their comfort zones. As a teenager, I was an exchange student myself (in a Chinese-American family in California) creating lifelong relationships with Chinese-American and African-American friends. I am a host-mother of eight full-year students in my home from Asian, European and South-American countries, as well as many shorter term international students. I have helped international university students to acclimate in local communities in Illinois. Powerfully the early years lay the groundwork for the future. My children grew up bilingually and my tri-cultural grandchildren are growing up trilingually. Today even more than before it is crucial for professionals to work together to help create environments for children where they can grow optimally in the cross-culturally vibrant world. The challenges facing educators in doing a good job in understanding the world are complicated and include familial and societal stresses, political tensions, economic hardships, difficulties in finding time to spend together, complicated relationships with nature and the environment, and our rapidly expanding knowledge of how our brains learn. I love collaborative projects. One such project brought together teacher education students with educators from South Korea, Finland and Ghana in their teaching methods class. Since then I have used videoconferencing regularly to bring interactions from other countries into my classrooms. As a teacher educator, I am most interested in pursuing teaching courses related to cross-cultural and international experiences promoting intercultural competencies while finding out about the host country's strengths, challenges and ideas.

My husband, who taught in the Czech Republic and Russia contributes to my life by sharing his Missouri upbringing and joy of travelling. Our home is a place for international gatherings and we have recently hosted educational groups from SouthKorea, Belgium, and Finland. My siblings (I am one of ten) and three daughters enrich my interactional and international awareness. Our mutual interactions and questions about the world, cultural negotiations, bilingual punning, nonverbal diversity and our own rootedness while learning with others, inform my life. My extended family's cultural tapestry is varied: from research experiences in Africa of my anthropologist sister, missionary brother in Taiwan, another sister and her husband's Pukhet Tsunami experience, two other sisters' teaching experiences across cultures, my own daughter's experiences in the Peace Corp, and multicultural families, collaborative work with European Union school partners and international students are examples of shared, ongoing and developing discussions. My family's get-togethers are complex cacophonies of sharing, laughter glued together with singing our hearts out in four-part harmony with always some international presence involved.

Regardless of many international experiences, being involved in my university's international efforts and Global Scholar program, I realize this is only a beginning in the palette of possibilities to feel connected with various parts of the world. I live between and among cultures in my heart and in my practical daily life. Yet, it feels like I am just starting to understand the world, the connectedness among us all. In varied phases of my life I can see myself having moved back and forth in NuriRobins et al. (2012) continuum from cultural pre-competence to cultural proficiency with the hope that as I grow in understanding the complexities of the world and people I interact with that integration would be more the context than anomaly in my everyday life. In thinking about this I created a term for my experience: a holographic self-identity which illustrates how the dimensions of life are sometimes apparent, sometimes hidden but still present. As in a hologram in a given cultural context the dimensions needed activate and become alive in that given context.

As a young child, I had a reoccurring dream about building peace in the world while learning with and from others and immersing myself in languages and cultures of others. In the dream, dressed in white, I hold a bouquet of white roses. Before me the rulers from all nations are lined up. I plead with each one, in their native language, that they would live in peace with all and hand them a rose. Such a sustaining dream has framed and guided my life powerfully in my individual journey as a teacher, scholar and a developing person.

As a result of writing this piece, I made a historical connection that prior to this moment was obscured from my view: this dream started occurring during the time of the Cuban missile crisis when the American and Soviet missiles were pointing at each other, right over the heads of my family members while I anxiously and actively feared for the wellbeing of my loved ones. This dream has just grown in depth in ways that, in retrospection I can say, built a vision for the purpose of my life. This dream consists of comfort, kinship and affection which reside in cultural proficiency. I often wondered why this dream had such a power over me, in its emotional depth, its eloquence and its piercing quality. Today I know. The two events were tightly separated in their own memory compartments. Not till the writing of this did I discover that all along, within me, the fearful child was reaching out to be a person of courage and the consolation was born through my dream of collaborative peace.

\section{Autobiography Impacting Instruction}

The three higher education colleagues, who found each other through serendipitous interactions, or what Palmer (2007) terms through capacity for connectedness, discovered a shared interest in growing as cultural beings and in our capacity as teachers. Not only our experience, but our interactions are helping us move towards who we want to be as teacher educators. From working on our own and grappling with issues related to identities as cultural beings, we have developed a collaborative voice that is more "plurivocal" (Connelly and Clandinin, 1990) than creating a single story (Adichie, 2009) about teacher educators. As we have learned to know each other better, we have learned to appreciate the personal, professional, cultural knowledge we each bring to our dialoguing. We have been brave enough to voice our individual stories, and have gained cultural wisdom while working together.

In our autobiographies, we represent many lenses; the female gender, mother, teacher, daughter, sister, grandmother, volunteer, colleague, collaborative, rural, urban, immigrant, professional, single-parent, counselor, religious believer, empowerer, alien, divorcee, widower and other voices. We participate in the role of traveler, early childhood educator, math educator, cross-cultural educator, planner, researcher, organizer, connector, advocate and communicator. These all intertwine to enable us to be CPIs who are aware of culture, ours and our students' in the classroom. We have become more aware of how these cultures can impact an individual on a daily, or moment basis. This impact can be on the learning situation, learning environment or in the personal realm. We share the common culture of being women teaching in teacher education programs. However, we also have specificity in teaching mathematics and early childhood, each carrying a connotation of being "scary" and "easy", respectively. This reflects our awareness of what our students' expectations are when they enter our classroom 
culture.

We each have pondered on the power of our interactions in becoming more aware culturally. Participating in various professional endeavors has given us the opportunity to reflect on our experiences and see how they impact us. It has provided us with empowering opportunities. Separately and combined we have written, presented, written course proposals and spent time pondering the possibilities. There is a humility that is born through experience that weaves together commonalities and curiosities of differences, both the outsider and insider experience. Through this work we have broken the silence by sharing the experiences to weave a richer view, or sew a quilt of diversity that opposes the "robbing of dignity" (Adichie, 2009) that our current political climate and the eroding of civility in public discourse with alternative facts, if not alternative realities, has shown to do. It is through these endeavors that we can hope to institutionalized the value of cultural competency.

The authors create classroom environments where diversity is valued by encouraging cross-cultural collaborations between countries and cultures, and across linguistic and disciplinary boundaries. We use tools like dialogue journals, cultural autobiographies and manipulatives so teacher candidates can develop and find their own teacher voices. Since we each have experienced the feeling of being the 'outsider' we can encourage our students to consider multi-perspectives. We create a space where they are comfortable enough to share their fears of deportation. Personal experiences shed light on our instructional decisions. We share previous teaching experiences with our students, children and grandchildren as examples with our teacher candidates. Through our shared experiences, and those experiences we create for our students, we hope to create an environment where each culture is recognized, valued and encouraged to prosper.

We have found that some of our students bring in stories of microaggressions, environmental indignities that communicate hostile, derogatory, or negative racial slights and insults toward groups of people (Sue et al., 2007) These microaggressions, intentional or not, appear as microassaults, microinsults, and microinvalidations, experiences that the authors have also experienced. Some tell stories of their educational journeys that clearly are intentionally inviting attitudes (Purkey, 2002) and that is why they are in our teacher education programs.

As teacher educators, you may ask, why should I care about the culture of my classroom? We, as teacher educators, need to remember that we are preparing teachers who will have students from many cultures in their classrooms. Will they only see homogeneity? Will they be blind to the diversity in their classrooms as has been the case in too many classrooms? We must prepare them to be efficient CPIs. If our students are uncomfortable when cultural discourse is happening, when they may view the instructor as "crossing" the line in their own culture, we must recognize this and provide strategies to welcome the diversity. We must help our teacher candidates to value the context of language and cultural experiences, as this is where the richness of life is lived out. To preserve the public classroom, our teacher candidates must be prepared to recognize and address racial bias and cultural discomfort. It is imperative that as teacher educators we not only model the virtues of CPIs, but we must also provide opportunities for our teacher candidates to discuss and reflect on their own cultural competence, perhaps through telling their own cultural story. Noddings (2005) suggests we do this through an ethic of care, where each "living other is more important than any theory". In the heart of caring is responsiveness which is crucial in raising a cadre of teachers who are culturally proficient. Eisner (1985) suggests that our experiences are "the product of both the features of the world and the biography of the individual. Our experience is influenced by our past as it interacts with our present". The power is that when we meet our teacher candidates and try to move them on the continuum they need to see who they are so that they can go to be who they are meant to be.

\section{Conclusion}

The context of teaching matters. Who we have as learners in our classes matters. The political climate of our society matters. Our qualifications, depth of knowledge and self-efficacy beliefs matter when we teach. How pedagogically nimble we are, matters as we encounter autobiographies of our students that differ from our own. Our sensitivities and hope matter. How and when to shift or to modify a methodology matters. Movement toward more culturally proficient instruction, best practices and democracy matter because each person becomes more visible. Caring about each learner matters. In doing so, we also respect and cherish our own growth as teachers who matter.

It is our hope that our teacher candidates find their own way to flourish, to make sense of who they are and how they forge connections, in the political arena that schools are situated in. That they would find and embrace their best teacher voice, anchored into their authentic self, their life history, their culture and roots. That they in turn could touch others, inspire and grow continually. This is the beauty and privilege of being a teacher.

\section{References}

Adichie, C.N., 2009. The danger of a single story [Video file]. Retrieved from https://www.youtube.com/watch?v=D9Ihs241zeg.

Antola Crowe, H., R. Wolffe and J. Hunzicker, 2016. Synergistic benefits and cultural competencies in a multidisciplinary PDS Partnership. In B. Cozza, B. \& P. Blessinger, P. (Eds.). University partnerships for community and school system development. UK: Emerald Group Publishing, 5־JB1]: 281-299.

Busse, S., C. Ehses and R. Zech, 2000. Collective research in autobiography as a method of the science of the subject. Forum: Qualitative Social Research, 1(2): 4-22. View at Google Scholar

Connelly, M. and J. Clandinin, 1990. Stories of experience and narrative inquiry. Educational Researcher, 19(4): 2-14. View at Google Scholar

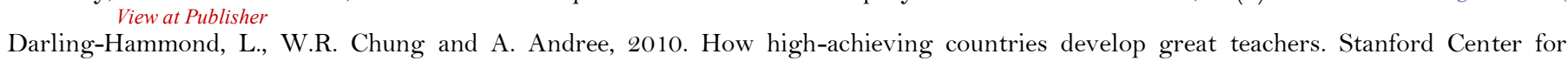
Opportunity
Policy https://edpolicy.stanford.edu/sites/default/files/publications/how-high-achieving-countries-develop-great-teachers.pdf
[Accessed May 10, 2017].

Eisner, E., 1985. Aesthetic modes of knowing. In E. Eisner (Ed.) Learning and teaching the ways of knowing; Eighty-fourth yearbook of the national society for the study of education. Chicago, IL: University of Chicago Press. pp: 23-36.

Noddings, N., 2005. The challenge to care in schools. Boston: Teachers College Press.

Nugent, P.M. and J.M. Grant, 2011. The changing number line: Preservice teachers' number sense and the importance of communication. In Donna F. Berlin \& Arthur L. White (Eds.). Science and mathematics education: International innovations, research, and practic es. Columbus, OH: International Consortium for Research in Science and Mathematics Education. pp: 123 - 134.

Nuri-Robins, K.J., D.B. Lindsey, R.B. Lindsey and R.D. Terrell, 2012. Culturally proficient instruction: A guide for people who teach. 3rd Edn., Thousand Oaks, CA: Corwin Press. 
Palmer, P.J., 2007. The courage to teach: Exploring the inner landscape of a teacher's life. San Francisco: Jossey-Bass.

Pinar, W.F., W.M. Reynolds, P. Slattery and P.M. Taubman, 1996. Understanding curriculum. New York: Peter Lang.

Pipher, M., 2002. In the middle of everywhere. New York: Harcourt.

Purkey, W., 2002. Foreword. In Schmidt, J. J.Intentional helping: A philosophy for proficient caring relationships. Upper Saddle River, NJ: Merrill, Prentice Hall. pp: 5-6.

Schön, D.A., 1987. Educating the reflective practitioner: Toward a new for teaching and learning in the professions. San Francisco: JosseyBass.

Sue, D.W., C.M. Capodilupo, G.C. Torino, J.M. Bucceri, A.M.B. Holder, K.L. Nadal and M. Esquilin, 2007. Racial microaggressions in everyday life: Implications for clinical practice. American Psychologist, 62(4): 271-286. View at Google Scholar | View at Publisher 